\title{
Distributed situation awareness in dynamic systems: theoretical development and application of an ergonomics methodology
}

Neville A. Stanton, Rebecca Stewart*, Don Harris*, Robert J. Houghton**, Chris

Baber**, Richard McMaster**, Paul Salmon, Geoff Hoyle***, Guy Walker, Mark S. Young, Mark Linsell****, Roy Dymott***** and Damian Green.

Human Factors Integration - Defence Technology Centre

BITlab, School of Engineering and Design, Brunel University, Uxbridge Middlesex, UB8 3PH, UK

*Human Factors group, School of Engineering, Cranfield University, Cranfield Bedfordshire, MK43 0AL, UK

**Department of Electrical and Electronic Engineering, University of Birmingham Edgbaston, Birmingham, B15 2TT, UK

***SEA, SEA House, PO Box 800, Fishponds, Bristol, BS16 1SU, UK

****Lockheed Martin UK Ltd - Integrated Systems

Building 7000, Langstone Technology Park, Havant, Hants, PO9 1SW

*****MBDA Missile Systems, Golf Course Lane, Filton, Bristol BS34 7QW, UK

The purpose of this paper is to propose foundations for a theory of situation awareness based on the analysis of interactions between agents (i.e., both human and nonhuman) in subsystems. This approach may help promote a better understanding of technology-mediated interaction in systems, as well as helping in the formulation of hypotheses and predictions concerning distributed situation awareness. It is proposed that agents within a system each hold their own situation awareness which may be very different from (although compatible with) other agents. It is argued that we should not always hope for, or indeed want, sharing of this awareness, as different system agents have different purposes. This view marks situation awareness as a 
dynamic and collaborative process that binds agents together on tasks on a momentby-moment basis. Implications of this viewpoint for development of a new theory of, and accompanying methodology for, distributed situation awareness are offered.

Keywords: agents, systems, theory, command and control, SA, teams

\section{DISTRIBUTED VERSUS OVERLAPPING SITUATION AWARENESS}

In this paper we present a description of Distributed Situation Awareness (DSA) that is system- oriented, rather than individual-oriented. We argue that this approach provides us with a means of examining SA in team working. Our aim is to develop measures of DSA that can support prediction of performance and inform the interpretation of observations made in the field, e.g., in terms of explaining possible mistakes, in terms of comparison of command and control across different organisations. Researchers such as Hollnagel (1993) and Hancock (1997) have made convincing arguments for the system's perspective in analysing human-machine interaction. The hierarchical and heterarchical relationships and interactions between structures and functions at different levels have certainly served human factors researchers well in the past (Wilson \& Corlett, 1995Rasmussen, 1986; Salvendy, 1997; Singleton, 1989; Meister, 1989; Vicente, 1999). In a review of contemporary team teamwork research, Paris et al (2000) found that most theories, models and taxonomies comprise a tripartite inputprocess-output approach from general systems theory. This seems to be a useful distinction for the development of a predictive model. Indeed the systems theoretic approach would enable different levels of description appropriate to the nature of the prediction being offered. The systems framework offers the possibility of analysing interactions and relationships at many different levels and focusing of specific interactions within sub-systems. Researchers have suggested that technical aspects of the system are part of the joint cognitive system (Hollnagel, 1993). Research into trust and technology suggests that there are shared traits between interpersonal trust and technological trust (Muir, 1994; Muir \& Moray, 1996). Ashleigh \& Stanton (2001) have shown that those shared traits included emotive constructs (i.e., confidence, respect, commitment and teamwork), cognitive constructs (e.g., understanding, ability, and expectancy), and behavioural constructs (e.g., reliability, performance and communication). The authors report that the people they interviewed did not 
distinguish between human or non-human agents when using these constructs. The idea of collaborative human and non-human SA agents seems to be a useful concept to carry forward into our theory.

We assume that, in distributed team work, cognitive processes occur at a systems, rather than individual level. Thus, if one takes Endsley's (1995) three-stage model of SA \{perception, comprehension, projection - which maps directly onto the tripartite input-process-output systems approach\}, it is possible to apply this to a 'system' as shown in table one. In this example, a handheld gas analyser is used to determine whether fumes from a chemical are at risky levels. Once a threshold has been exceeded, the fire-fighter carrying the device decides to evacuate the area. The Incident Commander, watching the fire-fighter, realises that there is a risk and orders the crew to return to vehicles.

Table one1: DSA in a part of a fire fighting system

\begin{tabular}{|l|l|l|l|}
\hline Agent & PERCEPTION & COMPREHENSION & PROJECTION \\
\hline Gas analyser & $\begin{array}{l}\text { Senses level of } \\
\text { toxic gas }\end{array}$ & $\begin{array}{l}\text { Calculates current } \\
\text { gas level and } \\
\text { compares against } \\
\text { threshold }\end{array}$ & $\begin{array}{l}\text { Indicates that gas } \\
\text { level could be } \\
\text { hazardous to } \\
\text { health if exposure } \\
\text { prolonged }\end{array}$ \\
\hline Fire-fighter \#1 & $\begin{array}{l}\text { Reads level on } \\
\text { meter }\end{array}$ & $\begin{array}{l}\text { Determines high } \\
\text { level equates to risk } \\
\text { to self }\end{array}$ & $\begin{array}{l}\text { Need to exit } \\
\text { building }\end{array}$ \\
\hline Incident Commander & $\begin{array}{l}\text { Sees fire- } \\
\text { fighter pause } \\
\text { in doorway }\end{array}$ & $\begin{array}{l}\text { Decides gas level } \\
\text { presents risk to crew }\end{array}$ & $\begin{array}{l}\text { Switch to } \\
\text { defensive } \\
\text { response }\end{array}$ \\
\hline
\end{tabular}

This is quite a simple example as it's linear - output from the gas analyser is input for the fire-fighter and, to a certain extent the fire-fighter's output is the Commander's input - but is serves to illustrate two factors that are important to the approach developed in this paper. First, the 'knowledge' that underlies DSA is distributed across the system. Second, there is implicit communication of information rather than detailed exchange of mental models. From the example in table one, we can claim that the gas analyser represents its readings through a display showing that thresholds have been exceeded. Thus, as some of the significant factors that will influence individual cognitive performance will involve the representation, transformation and 
manipulation of information, i.e., from perception to cognition to action, so too can the systems-level model address such factors. Indeed, much of the work into distributed cognition (Hutchins, 1991, 1995; Flor and Hutchins, 1995; Perry, 2004) has specifically addressed the questions of representation, particularly in terms of the ways in which artefacts (and their use by people) can be used to represent information in ways that can support the 'immediate' extraction of meaning by people (cf. the theory of affordances, Norman, 1988), or can be used to embed complex manipulations into simple actions. It must be emphasised at this point that the approach takes a systems view, rather than looking at individuals. Therefore current conceptions of DSA do not take individual variables into account. There are theories of SA that already do this very well, and the purpose of this paper is to focus attention at a higher level in the system. This does not mean that individual SA is dismissed; rather a systems analysis cannot be accounted for by summing independent individual analyses.

These fundamental ideas of situation awareness distributed in a system lead us to propose a set of tenets that could form the basis of a theory (Stanton et al, 2004). These propositions are as follows:

a. SA held by human and non-human agents. As table 1 shows, technological artefacts (as well as human operators) have some level of situation awareness (at least in the sense that they are holders of contextually-relevant information), in this case the presence of toxic gas.

b. Different agents have different views on the same scene. As table one shows, the gas analyser, fire fighter and Incident Commander all have different views on the scene, as illustrated in their perception, comprehension and projection of the incident.

c. Whether or not one agent's SA overlaps with that of another depends on their respective goals. Although they are part of the same fire fighting system, the goal of the gas analyser is to detect the level of toxic gas in the environment, the goal of the fire fighter is to determine the level of risk present in the environment and the goal of the Incident Commander is to decide on the appropriate response for his/her crew. In terms of Endsley's model of SA it could be that the different agents are actually 
representing different stages of SA, rather than microcosms of SA in themselves - the gas analyser perceiving, the fire-fighter comprehending, and the Incident Commander projecting

d. Communication between agents may be non-verbal behaviour, customs and practice (but this may pose problems for non-native system users). For example, the Incident Commander takes the pause by the fire fighter in the doorway as a signal that there is something wrong.

e. SA holds loosely-coupled systems together. The relationship between the gas analyser, fire fighter and Incident Commander is held together by the by their respective levels or stages of awareness on the presence of toxins in the environments and the most appropriate response.

f. One agent may compensate for degradation in SA in another agent. For example one fire fire-fighter may be unaware of the level of toxins in the environment until he is informed by the gas analyser, another fire fire-fighter or the incident commander.

The types of incident that we are exploring can be considered in terms of Klein's (1989) notions of Naturalistic Decision Making, i.e., agents in the field are able to draw upon their experience and expertise to make rapid diagnosis and to perform effective actions in very limited timeframes. In a similar fashion, Smith and Hancock (1995) propose that, "SA is the up-to-the minute comprehension of task relevant information that enables appropriate decision making under stress." [Smith and Hancock (1995), p.59]. As our theory of SA operates at a systems level, it takes a different perspective to the individual and shared SA approaches. We feel that the shared SA approach could misdirect attention to inappropriate aspects of the task, where as there are points in tasks where SA may overlap for brief periods in distributed team working. Distributed SA requirements are not the same as shared SA requirements however. Shared SA implies shared requirements and purposes whereas distributed SA implies different, but potentially compatible, requirements and purposes. 
Our approach assumes, therefore, that DSA can be defined as activated knowledge for a specific task within a system. This echoes the notion of Bell and Lyon (2000) that, "SA could be defined as knowledge (in working memory) about elements of the environment” [Bell and Lyon, 2000, p. 142]. Taking this notion into the realm of distributed cognition, therefore, allows us to propose that a situation requires the use of appropriate knowledge (held by individuals, captured by devices etc.) that relates to the state of the environment and those changes as the situation develops. For the model presented in this paper, the 'ownership' of this knowledge is initially at the system, rather than individual level. This notion could be further extend to include 'meta-SA', where its knowledge of other agents' knowledge is contained in the system, such that each agent could potentially know where to go when they need to find something out.

\section{CASE STUDY ON TYPE 23 FRIGATE OPERATIONS CONTROL ROOM AT HMS DRYAD}

In order to apply the ideas of DSA to command and control, we have spent time at HMS Dryad (which is the head quarters of the Royal Naval School of Maritime Operations, where there are a number of land-based operations control room simulators) collecting data on anti-air warfare, surface and sub-surface threat tasks. The EAST (Event Analysis of Systemic Teamwork) methodology (see Walker et al, 2005 in this issue for a more in-depth discussion of the approach) takes data from Hierarchical Task Analysis (Annett, 2005 - Annett et al (2000) have demonstrated how HTA can be used to capture the principle components of team work in an AntiSubmarine Warfare task), direct observation of tasks, and debriefing interviews using the Critical Decision Method (Klein \& Armstrong, 2005) to produce three main representations of a system: a social network, a task network and a knowledge network. We believe that these networks offer different, but compatible, facets of systems representation. At the highest level of representation the social network represents communication relations between people in the system (Houghton et al, 2005). In the interests of brevity, this representation will not be shown within the current paper. At the next level down, the task network shows the relationship between goals of different agents in the system. At the lowest level of representation is the knowledge network, which shows the relationship between classes of information that the system knows about in order to perform effectively. 
For the purposes of the HMS Dryad type 23 operations control room studies, an observer was able to sit directly behind a crew member and to plug into their console, allowing them to hear all radio exchanges. The AAWO (Anti-Air Warfare Officer) was observed during the air threat and the PWO (Principal Warfare Officer) was observed during the subsurface and surface threats. All forms of communication were recorded, including: verbal exchanges not communicated via radio, hand gestures, and written communication (on paper). Figure one shows part of the type 23 operations room.

Within these scenarios there are four main agents: the officer of the watch (OOW), the PWO, the AAWO, and the Captain. The OOW is an officer on the ship's bridge who maintains the visual lookout and controls the ship. The OOW can overrule the manoeuvring orders from the operations room should he consider them to be dangerous. The PWO is responsible in the tactical handling of the ship and the integrated use of its weapons systems and sensors. The PWO will take a tactical command role in multi threat missions. The AAWO is responsible for plan of defence in response to an air attack. The Captain will oversee the operations room. In addition to personnel the ship has a computer based command system which can communicate and control weapons and sensor systems which allow information to be passed independently of the command system itself. An illustration of the seating layout and accompanying glossary are in figure two and table one two respectively.

Originally the type 23 frigates primary task was of anti-submarine warfare. More recently their role includes air and surface warfare. All three scenarios fit into similar task models. In order to manage this scenario, a number of goals need to be addressed: plan resources and strategy, control external resources, posture platform for attack, identify and classify targets, assess threat and allocate targets, engage targets and re-allocate assets and weapons. 


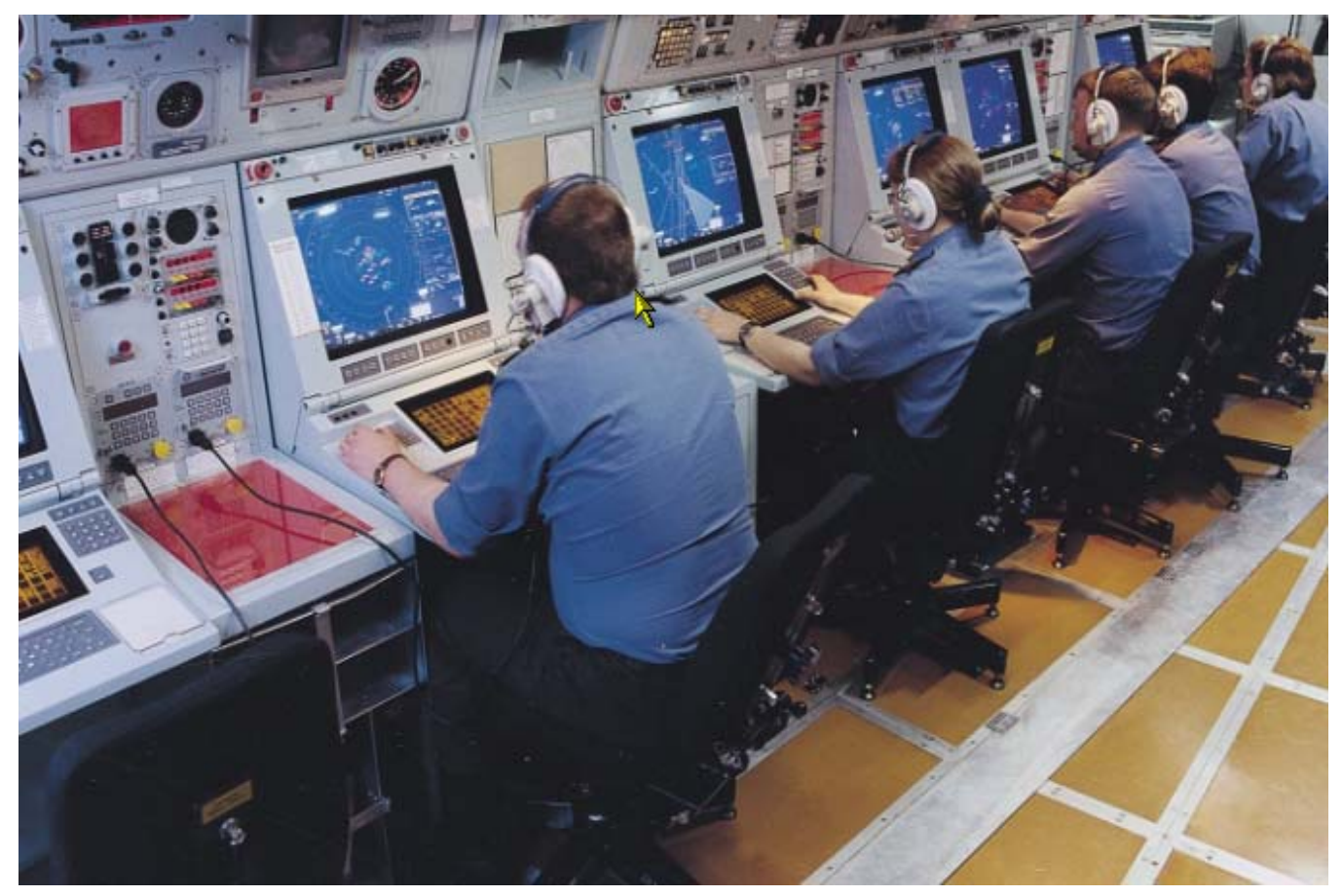

Figure 1. Illustration of workstations onboard a Type 23 frigate showing a subset of picture compilers.

\begin{tabular}{|l|l|}
\hline SPC & \\
\hline SPS & \\
\hline TPS & \\
\hline APS & \\
\hline HC & \\
\hline AcPC & \\
\hline
\end{tabular}

Forward

\begin{tabular}{l|l|}
\hline \multirow{1}{*}{$*$} & ASWD \\
\cline { 2 - 2 } *ASWPS \\
\hline ASWO \\
\hline PWOptain \\
\cline { 2 - 2 }
\end{tabular}

\begin{tabular}{|l|l|l|l|}
\hline & EWD & MD & $\begin{array}{l}\text { GUN } \\
\text { CONTROL }\end{array}$ \\
\hline
\end{tabular}

Figure 2. Seating lay out of Type 23 frigate operations room *denotes where the AAWO was standing 
Table 2. The main agents involved in the mission

\begin{tabular}{|l|l|}
\hline $\begin{array}{l}\text { Agent Title or } \\
\text { Acronym }\end{array}$ & Explanation of Acronym \\
\hline Captain & \\
\hline PWO & Principal Warfare Officer \\
\hline AAWO & Anti Air Warfare Officer \\
\hline ASWPS & Anti-Submarine Picture Supervisor \\
\hline SPC & Surface Picture Controller \\
\hline EWD & Electronic Warfare Director \\
\hline MD & Missile Director \\
\hline HC & Helicopter Controller \\
\hline APS & Air Picture Supervisor \\
\hline Off Ship & Other ships, aircraft etc \\
\hline Duty Staff & \\
\hline OOW & Officer Of the Watch \\
\hline ASWD & Anti Submarine Warfare Director \\
\hline ASW & Anti Submarine Warfare Officer \\
\hline SPS/ Surface & Surface Picture Supervisor \\
\hline Harpoon & \\
\hline CY & Communication Yeoman \\
\hline AcPS & Action Picture Supervisor \\
\hline & \\
\hline
\end{tabular}

The task model shown in figure three, illustrates the relationship between these goals. 


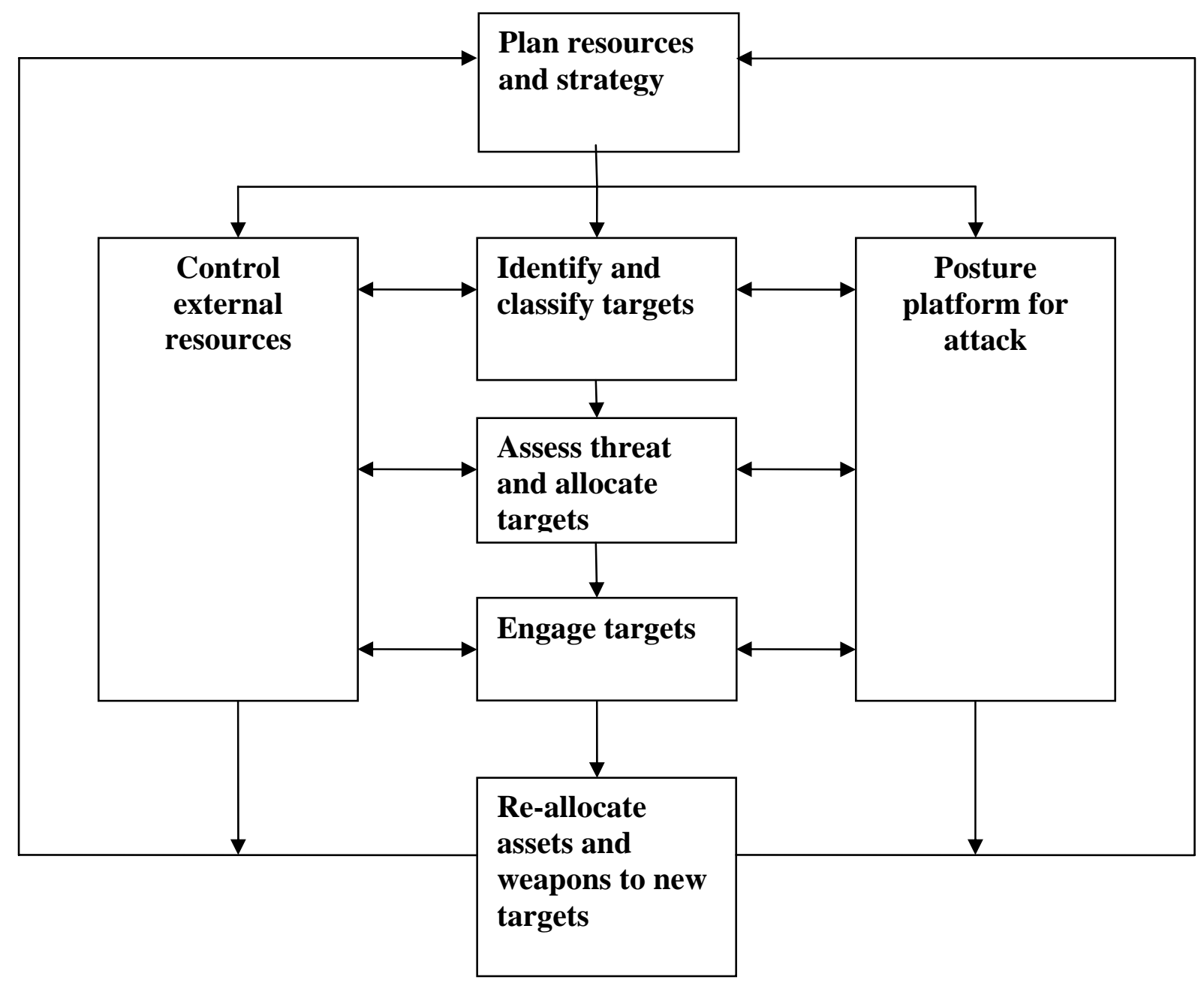

Figure 3. Illustration of the task network representation for a Type 23 frigate

Before the mission, the planning of resources and strategy are undertaken. During the mission the central tasks are performed concurrently by different parts of the team. New targets are identified and classified by the picture compilers and picture supervisors. The targets are then assessed and prioritised by the AAWO and PWO, who allocate assets and weapon systems to the high priority threats. The targets are then engaged by the assets and weapon systems as appropriate, and the degree of success is assessed. Successfully damaging or deterring a target frees up the asset or weapon system for new allocation. Missed targets may require reallocation. At the same time as all of this activity is being undertaken, the platform is being postured to optimise the engagement or the ability to evade enemy weapons. There is also a requirement to coordinate with other platforms and control other external resources 
(such as fighters and helicopters). Thus the whole operation demands considerable coordination of both internal (to the platform) and external resources and assets to manage a mission and deal with threats.

The majority of communications onboard the type 23 frigate are verbal, via the radio circuits. The PWO and AAWO have access to 20 external circuits, of which there are four major nets. Internally there is one main 'open line' with up to 40 point to point interphones. This method of communication has interesting implications for DSA, and has proven advantages in other areas (e.g., ATC). Although the personnel sit sideby-side they communicate via headsets and microphones and their visual attention is focused on the displays in front of them. For some tasks there may only be marginal advantage to be gained by the physical co-location of the team members as noted by Stanton et al (2002). The common battle-space picture, however, is built on the status displays and screens in front of the AWO and PWO. This makes co-location of these roles extremely important for a coordinated response. The subsurface and surface battles are usually fought over one net while the air battle is usually fought over another. The command open line is used by the captain, the AAWO, PWO, OOW, ASW Director, Duty Staff, EW Director, Missile and Gun Director, Communications Yeoman, and on a part time basis the helicopter controller. In addition to these radio channels crew members spoke face to face and used hand written notes. Pointing to the screens was also observed when matters need to be clarified.

The deepest level of analysis and representation is provided is the knowledge network, which describes the things that the system has to attend to in different phases of activity. The task network will be used to frame the knowledge network, to show knowledge network relevant to different goals of the system. One of the advantages of defining network models is that it is then possible to consider the potential effects of changes in those networks. For example, what would be the effects of changing the task, social or propositional networks? Would DSA be improved, remain the same or be adversely affected? Similar questions could be proposed with respect to mission effectiveness, workload, error rates, and timeliness of the systems response. Our initial studies have focuses on the modelling of contemporary system networks however, as illustrated in the following section. 


\section{DSA Methodology}

The DSA methodology comprises three main parts. In the first part, the knowledge owned by each party in each phase of the operation is elicited. Critical Decision Method has been used for this task. The second part is to extract 'knowledge objects' from the Critical Decision Method. Content Analysis has been used for this task. The third and final part is to represent the relations between 'knowledge objects' and identify in which phase(s) they are activated. Propositional Networks were used for this task, comprising 'subject', 'relation' and 'object' network structures of the knowledge required by the system to describe any given situation. Further details on the procedure and examples of the results follow.

\section{Part 1: Elicit the knowledge owned by each party}

Flanagan (1954) developed an interviewing protocol that allowed him to investigate 'critical incidents' in aviation. The technique employs a semi-structured interview to elicit key factors in accounts of incidents. In Flanagan's (1954) approach, the method was used as a vehicle for interviewing groups of respondents (as opposed to individuals). The interview could commence with a broad question, such as "Can you think of any incident or near-miss or event which happened to you, or a colleague, which could have resulted in an accident, given other circumstances?” (Kirwan, 1994, p.66). The idea is that respondents produce accounts of incidents that can then be discussed.

In recent years, the study of decision-making in real-world situations has received a great deal of attention. While much of the work involves observation, there is also an emphasis on the use of interviews to collect information. The Critical Decision Method (Klein, 1989) is a form of critical incident technique. According to Klein (1989), “The CDM is a retrospective interview strategy that applies a set of cognitive probes to actual non-routine incidents that required expert judgment or decision making” [Klein, 1989, p. 464]. In this approach, the interview proceeds through a series of four stages: briefing and initial recall of incidents; identifying decision points in a specific incident; probing the decision points; checking. 
The Critical Decision Method (CDM) makes use of information provided during observation of a scenario and from post-hoc discussions. This information is elicited and structured using the probe questions defined by O'Hare et al. (2000), as shown in table 3. A subject matter expert was interviewed and CDM analyses were conducted for the air threat scenario, subsurface threat and surface threat scenario (only the first of these three scenarios is presented here due to space limitations).

Table 3. CDM probes (O’Hare et al 2000)

\begin{tabular}{|l|l|}
\hline Goal Specification & What were your specific goals at the various decision points? \\
\hline Cue Identification & $\begin{array}{l}\text { What features were you looking for when you formulated your decision? } \\
\text { How did you know that you needed to make the decision? } \\
\text { How did you know when to make the decision? }\end{array}$ \\
\hline Expectancy & $\begin{array}{l}\text { Were you expecting to make this sort of decision during the course of the } \\
\text { event? } \\
\text { Describe how this affected your decision making process. }\end{array}$ \\
\hline Conceptual & $\begin{array}{l}\text { Are there any situations in which your decision would have turned out } \\
\text { differently? } \\
\text { Describe the nature of these situations and the characteristics that would have } \\
\text { changed the outcome of your decision. }\end{array}$ \\
\hline $\begin{array}{l}\text { Influence of } \\
\text { uncertainty }\end{array}$ & $\begin{array}{l}\text { At any stage, were you uncertain about either the reliability of the relevance } \\
\text { of the information that you had available? } \\
\text { At any stage, were you uncertain about the appropriateness of the decision? }\end{array}$ \\
\hline Information integration & $\begin{array}{l}\text { What was the most important piece of information that you used to formulate } \\
\text { the decision? }\end{array}$ \\
\hline Situation Awareness & What information did you have available to you at the time of the decision? \\
\hline Situation Assessment & $\begin{array}{l}\text { Did you use all of the information available to you when formulating the } \\
\text { decision? } \\
\text { Was there any additional information that you might have used to assist in } \\
\text { the formulation of the decision? }\end{array}$ \\
\hline Options & $\begin{array}{l}\text { Were there any other alternatives available to you other than the decision you } \\
\text { made? }\end{array}$ \\
\hline $\begin{array}{l}\text { Decision blocking - } \\
\text { stress }\end{array}$ & $\begin{array}{l}\text { Was their any stage during the decision making process in which you found } \\
\text { it difficult to process and integrate the information available? } \\
\text { Describe precisely the nature of the situation }\end{array}$ \\
\hline Basis of choice & $\begin{array}{l}\text { Do you think that you could develop a rule, based on your experience, which } \\
\text { could assist another person to make the same decision successfully? } \\
\text { Why/Why not? }\end{array}$ \\
\hline Analogy/generalisation & $\begin{array}{l}\text { Were you at any time, reminded of previous experiences in which a similar } \\
\text { decision was made? } \\
\text { Were you at any time, reminded of previous experiences in which a different } \\
\text { decision was made? }\end{array}$ \\
\hline
\end{tabular}

Part 2: Extract 'knowledge objects'

In order to convert the CDM tables into propositions, a Content Analysis is performed. In the first stage, this simply means separating all content words from any function words. For example, in response to one of the CDM probes the SME answered that the "Process is scripted but the situation determines the plan e.g. the nature of threat, degree of intelligence available, climatic conditions” would be 
reduced to the following knowledge objects: ‘threat', 'intelligence' and 'weather'. Working through the table leads to a set of knowledge objects. These are checked to ensure that duplication is minimised and then used to construct the propositional network.

In our interpretation of these activities we identify a network of knowledge objects. We have defined knowledge objects as the entities in the world that people detect, classify and manipulate. For example, knowledge objects would comprise knowledge of own and enemy land, air and sea assets (and the capabilities of these assets), targets, priorities, radar bandwidths, plan and strategies. For every set of phenomenon in the world there are potential knowledge objects. In this way we have interpreted the battle space as a network of knowledge objects rather than a technological network. This is not to deny the importance of the technological network, but to state that it is the correct activation of the knowledge network that ensures the whole system performs effectively.

The idea that 'knowledge' can be represented in the form of a network has been a major source of discussion of memory in cognitive psychology since the 1970s. Initially, researchers used Semantic Nets as a way of representing the association between items within a concept. Such an approach gave rise to theoretical insights such as spreading activation (Quillian, 1969; Collins and Loftus, 1975). The basic premise is that an item of knowledge will be easier to process if it has a high level of activation. According to Collins and Loftus (1975), other nodes linked to this active node also become activated, i.e., "The spread of activation constantly expands, first to all the nodes linked to the first node, then to all the nodes linked to each of these nodes, and so on” [Collins and Loftus, 1975, p. 408]. One way of considering a semantic network is that it is like the 'concept mapping' idea, i.e., one writes a single word in a box and then creates more boxes that link to this initial word.

Part 3: Represent the relations between 'knowledge objects' and their activation Propositional Networks are like semantic networks in that they contain nodes (with words) and links between nodes, but differ in two ways. First, the words are not necessarily randomly added to the network but involve the definition of propositions. A proposition is a basic statement, i.e., “..the smallest unit about which it makes sense 
to make the judgement true or false" [Anderson, 1980, p.102]. Second, the links between words are labelled to define the relationship between propositions. These relations might be in terms of subject and object (in grammatical terms), with a corresponding relation term. On the basis of such descriptions, it is possible to claim that one can produce dictionary-like definitions of concepts through the application of basic propositions and operators (Ogden, 1987).

From the propositions derived through content analysis from the CDM tables, it is possible to construct an initial propositional network to show the knowledge that is related to this incident. The propositional network consists on a set of nodes that represent objects, e.g., sources of information, agents, etc. that are linked through specific operators. From this network, it should be possible to identify required information and possible options relevant to this incident.

In the initial descriptions, the operators are simple relations such as 'causes', 'knows', 'has' 'is'. Thus, the example knowledge objects, 'platform', 'intent', 'weapons' and 'threat' would be represented as shown in figure six.

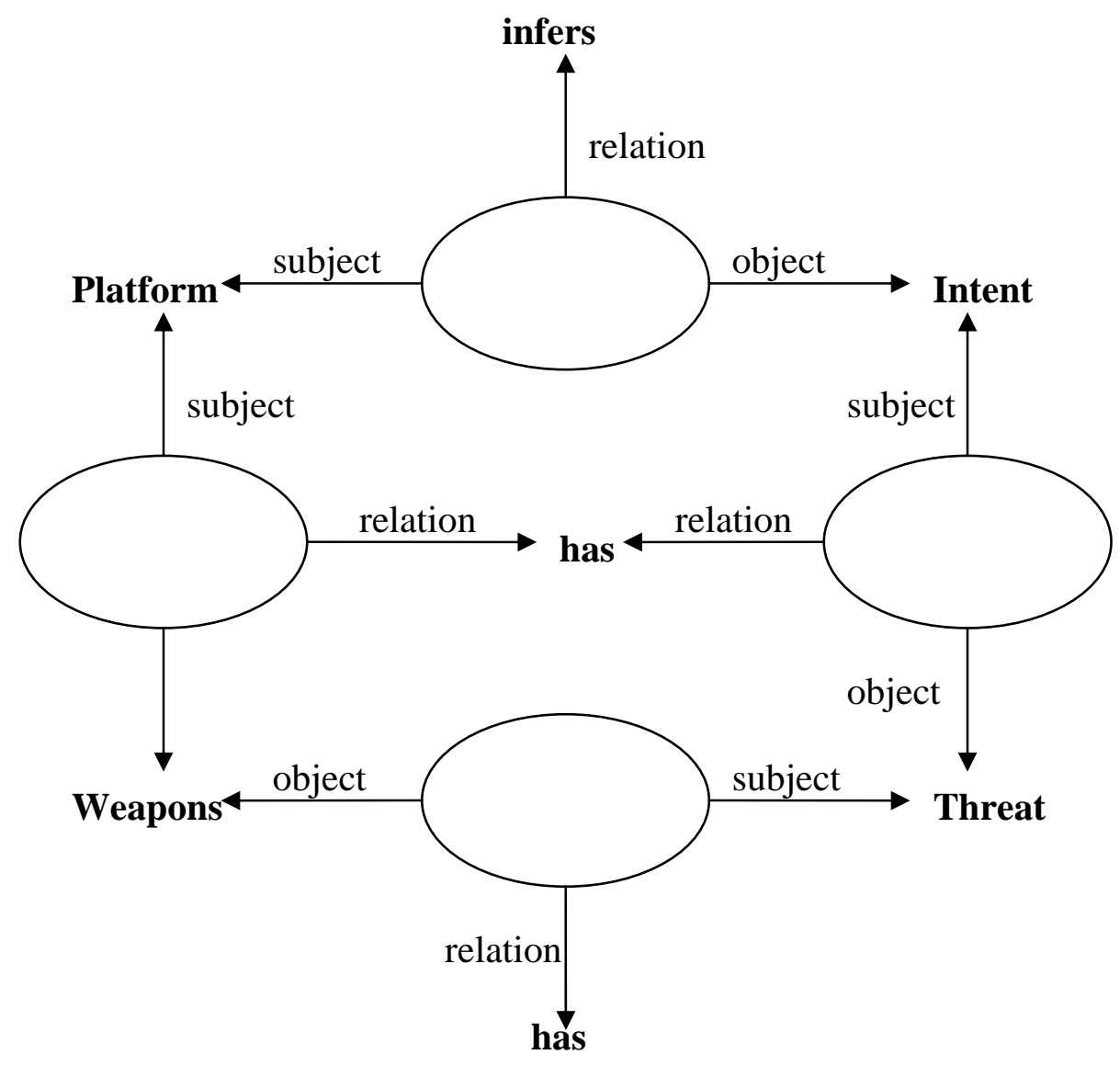


Figure six. A propositional network for command and control.

The justification for using a propositional network in this manner is that it represents the 'ideal' collection of knowledge for a mission (and is probably best constructed post-hoc). As the incident unfolds, so participants will have access to more of this knowledge (either through communication with other agents or through recognising changes in the incident status). An advantage of producing such a diagram is that, through use of colour-coding, it is possible to indicate in a simple, visual manner the relationship between specific agents and specific objects over the course of a mission. As the mission unfolds, so different nodes in this network will become active. The active nodes might be relevant only to one or two agents within the system. For example, the situation described began with planning resources and strategy. This would cause the nodes relating to <intelligence $>$, $<$ platform $>$, <intent $>$, < weapons $>$, $<$ scenarios $>$, $<$ threat $>$ and $<$ engage $>$ to be active. As the mission progresses, so the activation of nodes alters. Where there are jointly active nodes however, it is necessary to ensure some level of communication across agents. The knowledge network provides a graphical representation of the ideas and forms the basis for a distributed theory of situation awareness that is being developed from the work (Stanton et al., 2004).

The complete knowledge network for the surface, sub-surface and air threat tasks is shown in figure 8 (this figure was created using the WESTT software (Houghton, Baber, and Cowton, 2005) for construction of propositional networks). There are some sixty four knowledge objects in total which describe the total situation for the system under analysis. The knowledge network makes no reference to any particular job roles, and technology is only referred to in a general sense (such as weapons, satellite, radar and sonar). Whilst this is a general system-level representation, activation of any of the knowledge objects has been identified with particular tasks from the task network as shown in figures 9 to 15. As described in the task network analysis, the knowledge network illustrated in figure 9 is performed prior to the mission and then the knowledge networks illustrated in figures 10 to 15 are performed concurrently by different parts of the team and technological system. This activation 
of the knowledge network illustrates the distributed situation awareness of the system in a very literal sense.

Figure 9 shows the knowledge objects activated in the planning of resources and strategy. Figure 10 shows the knowledge objects activated in the identification and classification of targets. Figure 11 shows the knowledge objects activated in the assessment of threat and allocation of weapons and assets to targets. Figure 12 shows the knowledge objects activated in the engagement of targets. Figure 13 shows the knowledge objects activated in the reassessment of target engagement success and the reallocation of weapons and assets to new targets. Figure 14 shows the knowledge objects activated in the control of external resources. Figure 15 shows the knowledge objects activated in the posturing of the platform for attack. These data are derived from the CDM's and HTA as described earlier and were validated by Subject Matter Experts. Analysis of the knowledge object activated by each phase was conducted and is presented after the figures. 


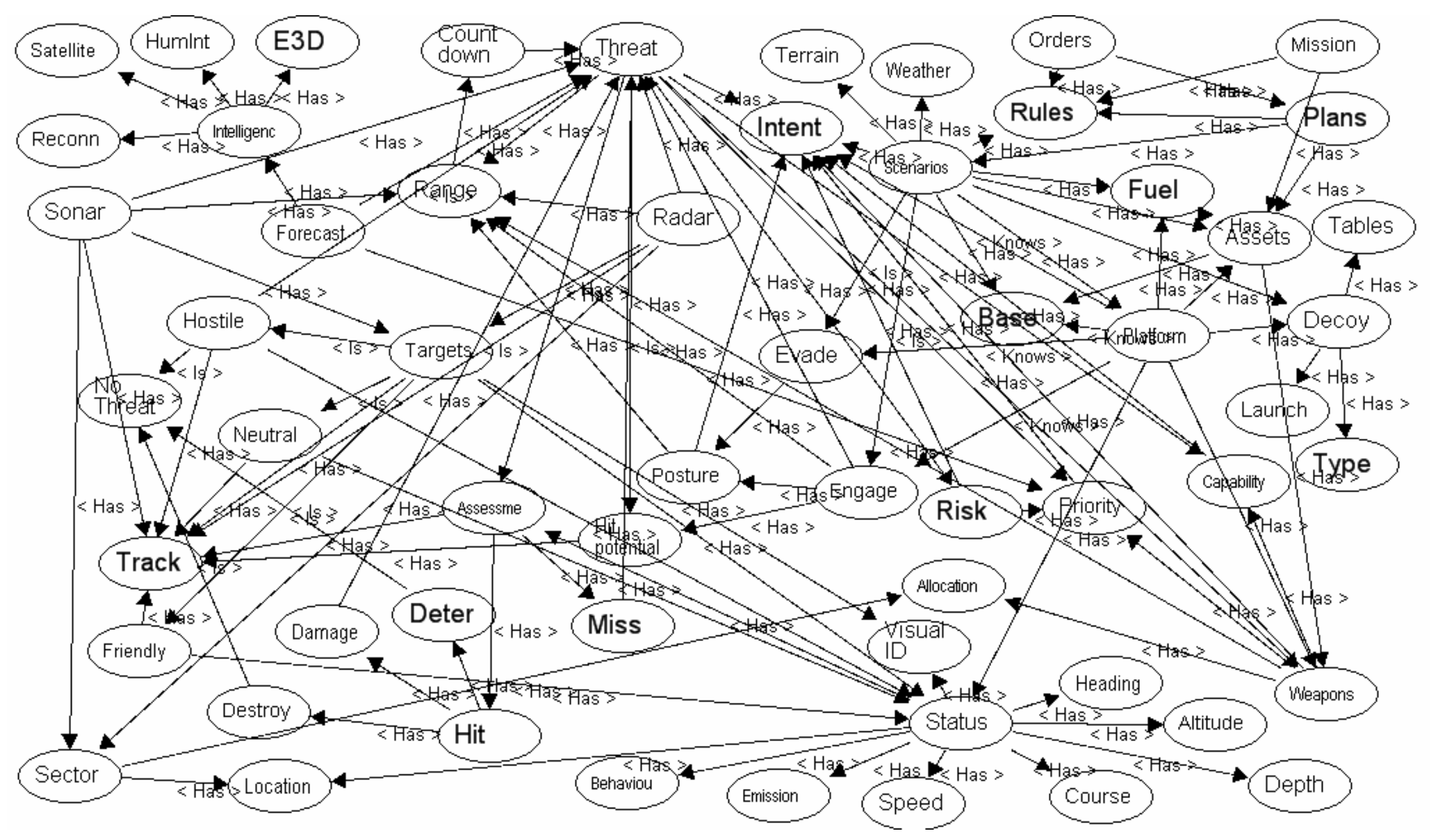

Figure 8. Propositional network for air, surface and sub-surface threat tasks 


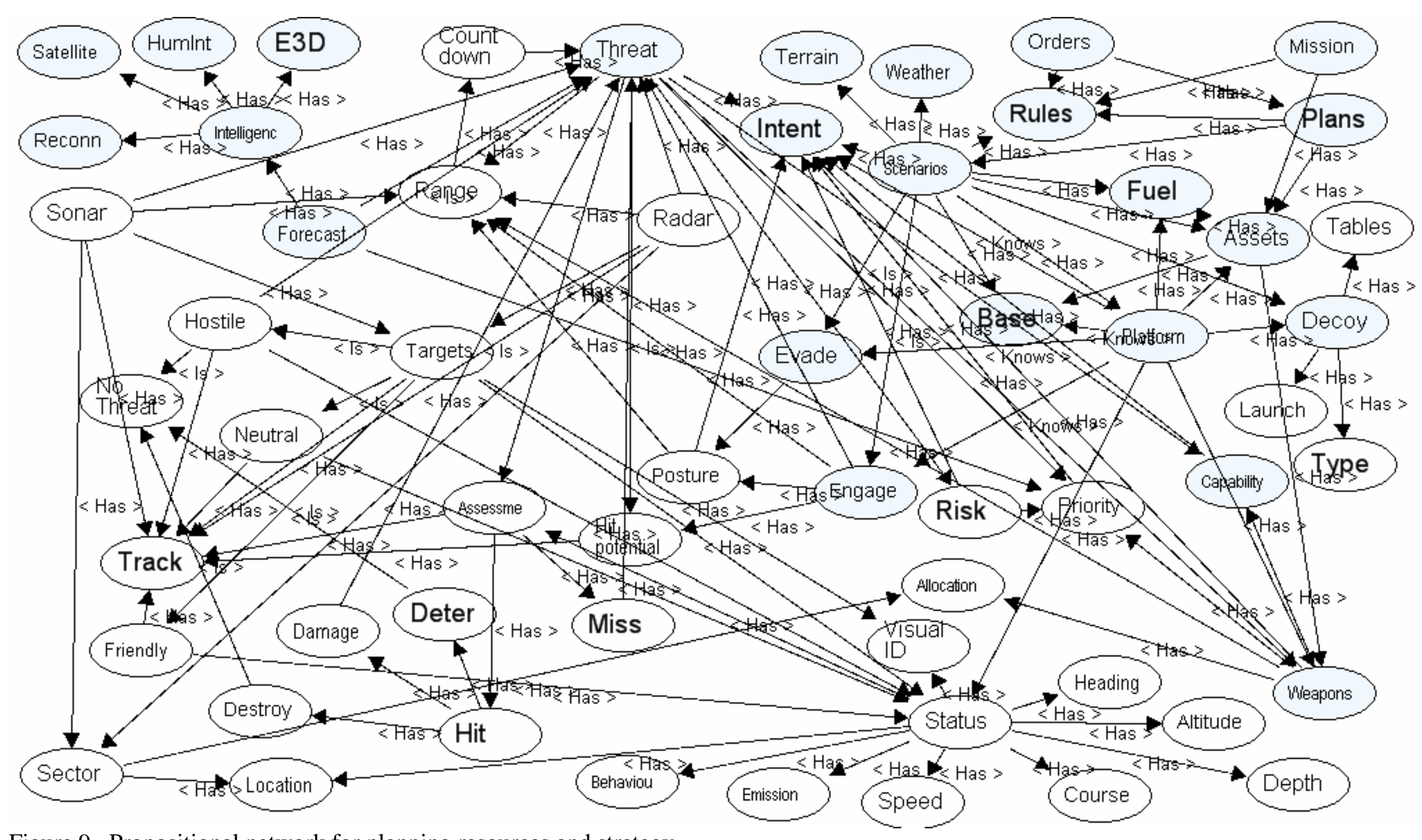

Figure 9. Propositional network for planning resources and strategy 


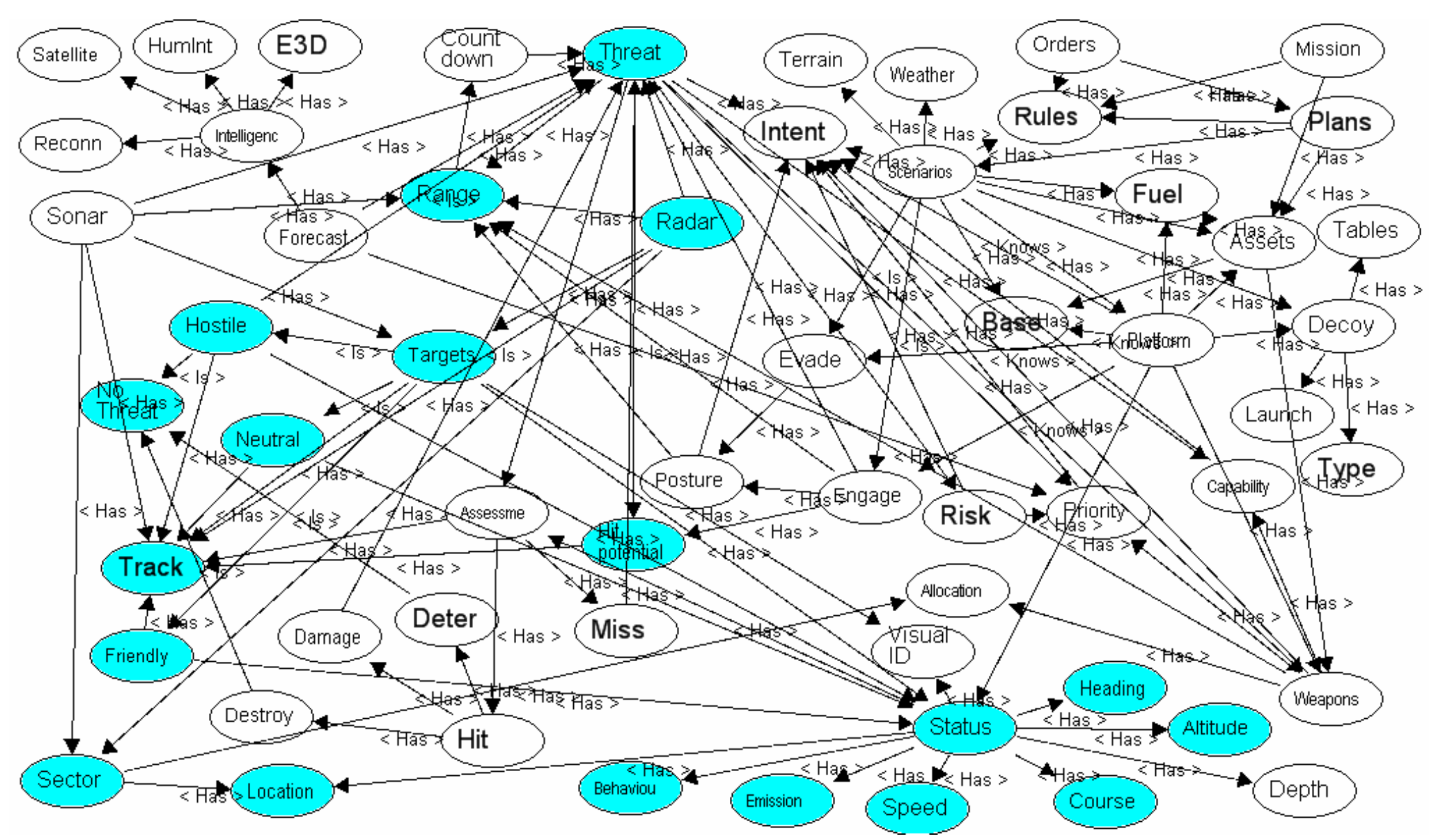

Figure 10. Propositional network for identifying and classifying targets 


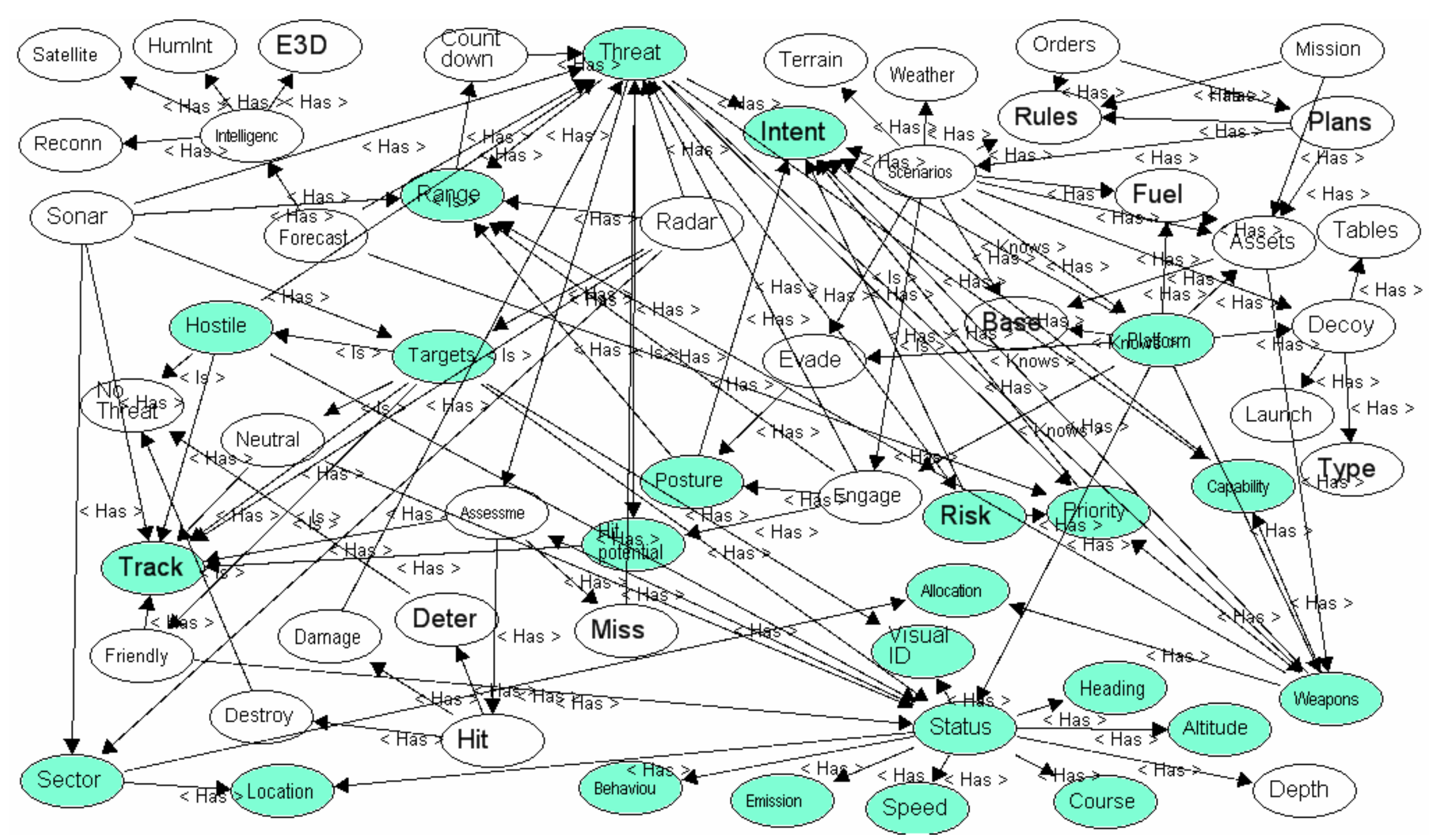

Figure 11. Propositional network for assessing threat and allocating targets 


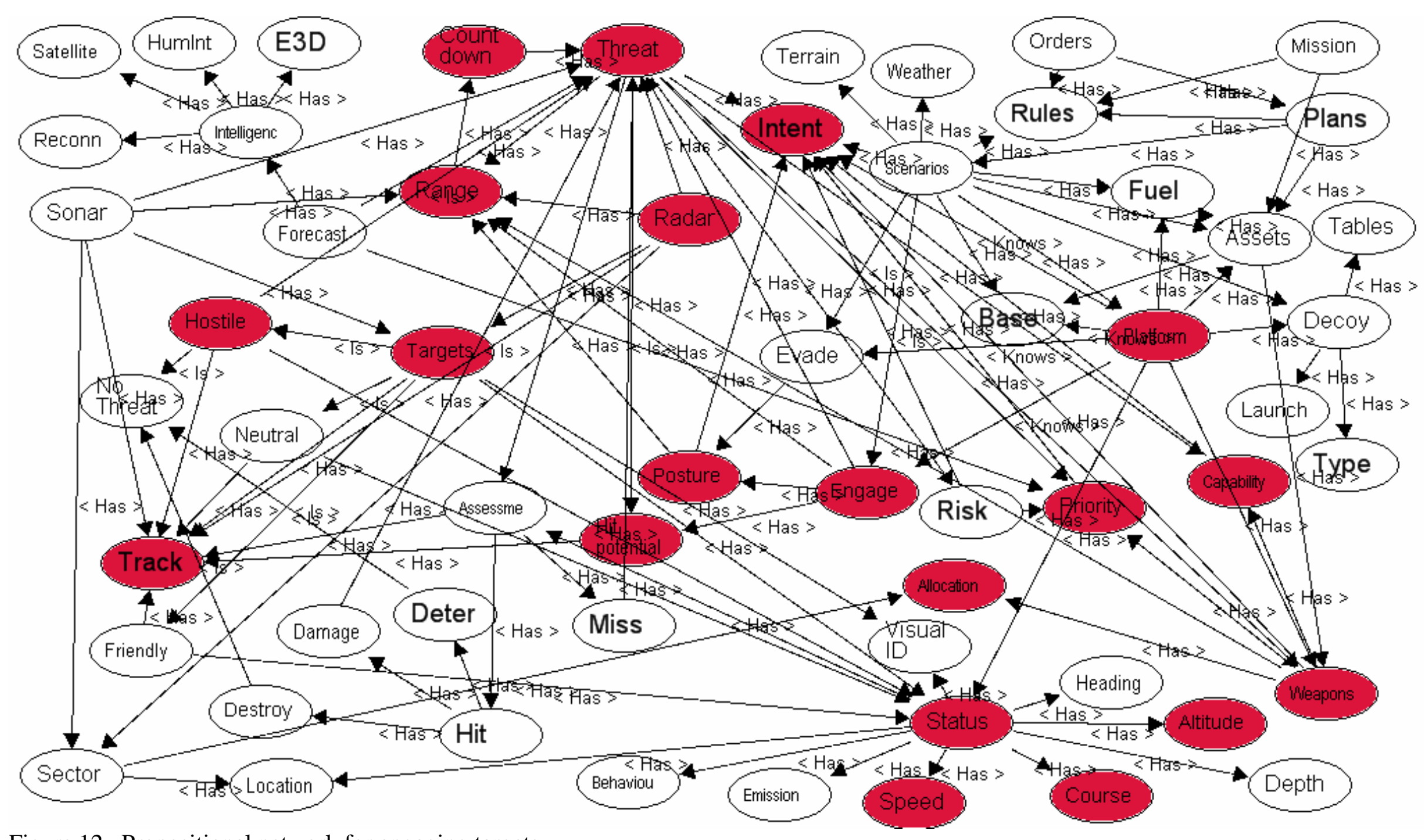

Figure 12. Propositional network for engaging targets 


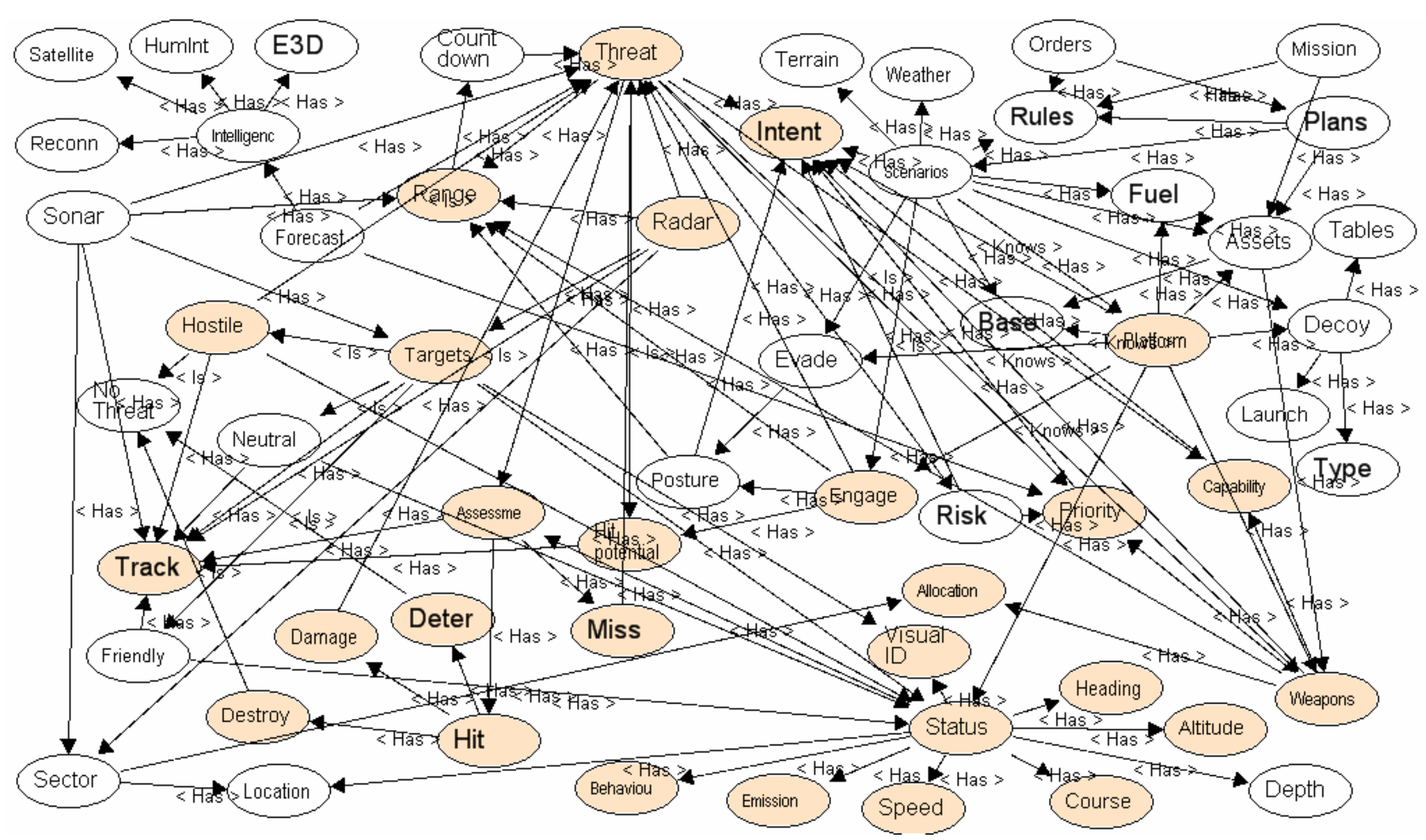

Figure 13. Propositional network for re-assessing targets and allocating weapons to new targets 


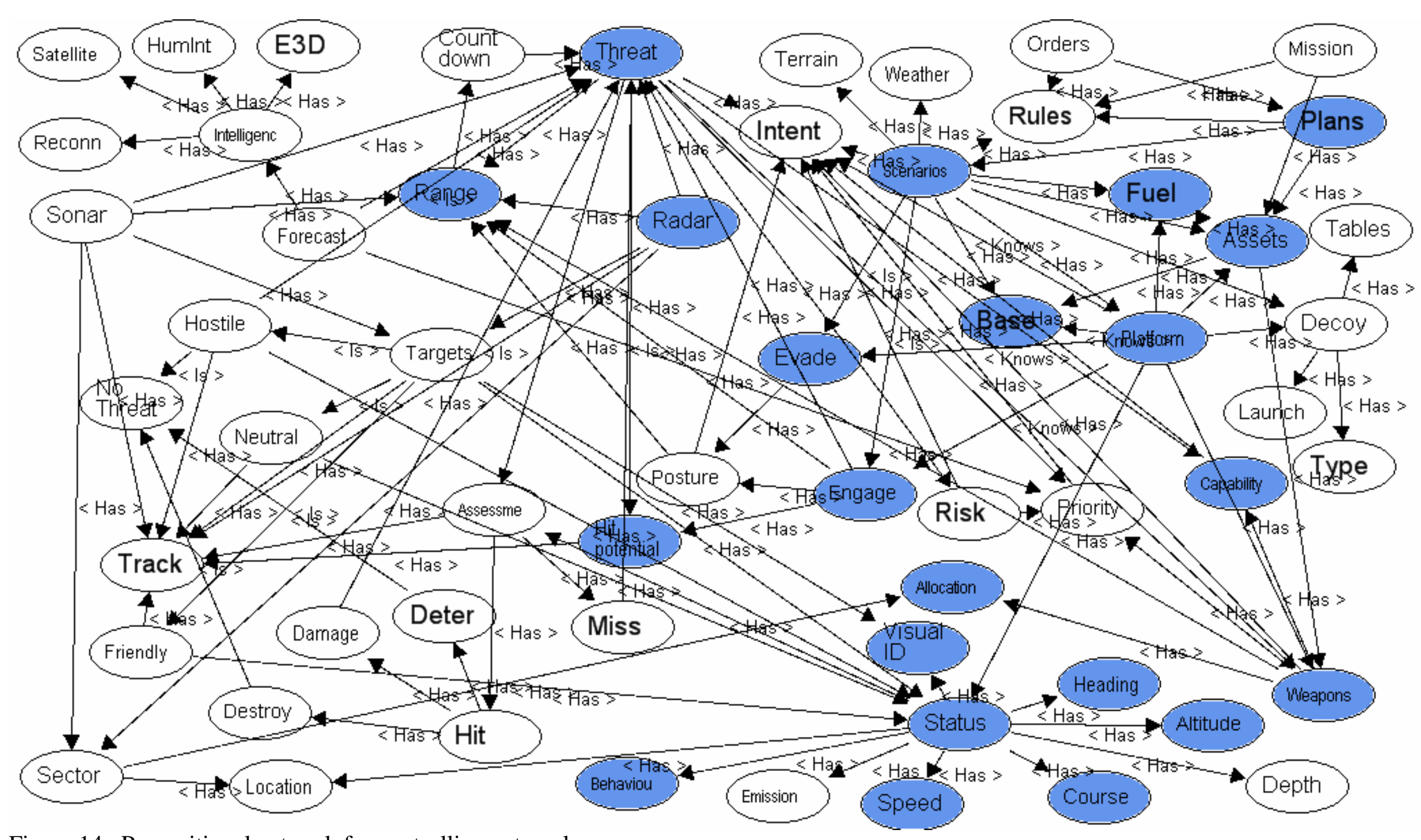

Figure 14. Propositional network for controlling external resources 


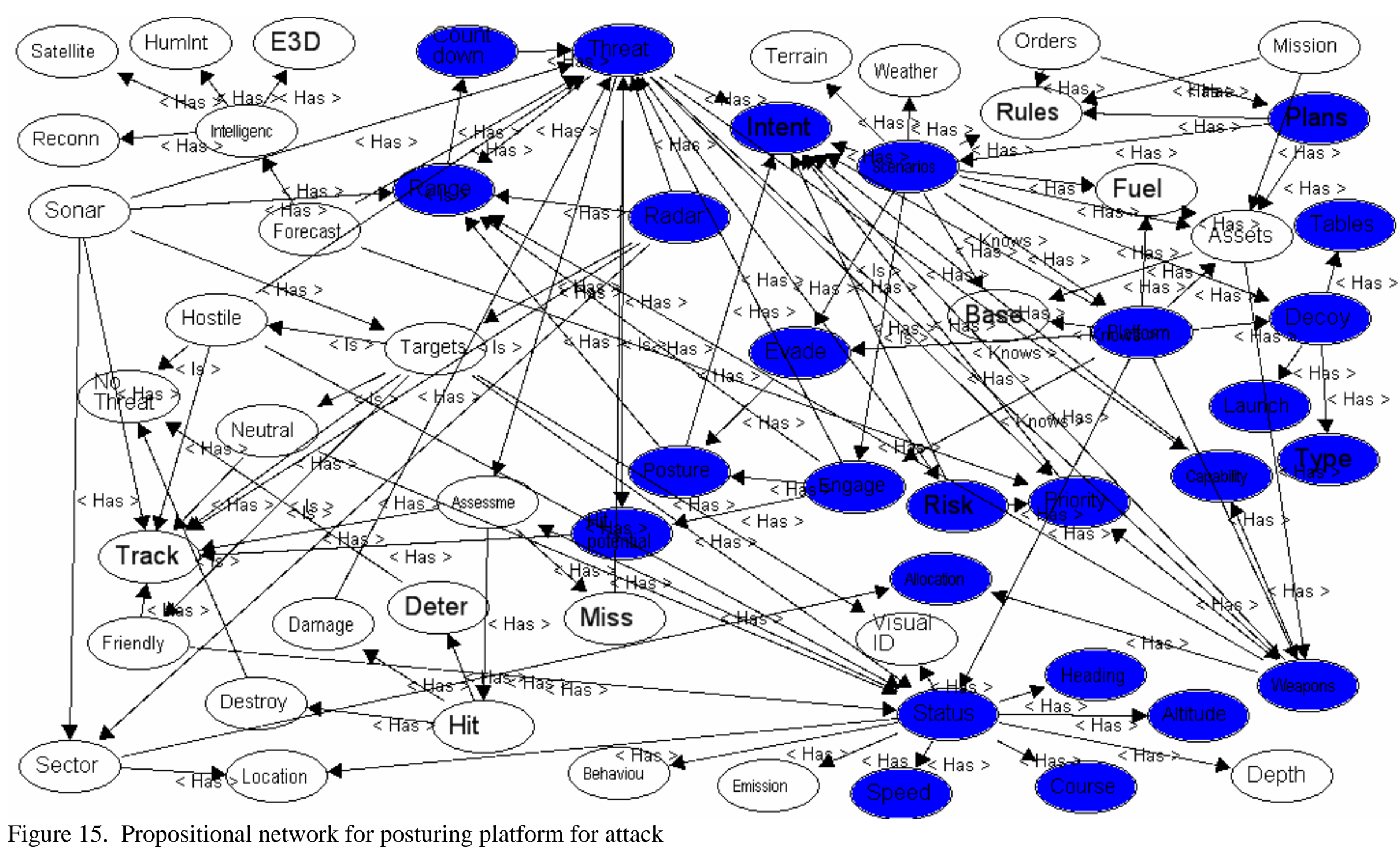

Figure 15. Propositional network for posturing platform for attack 
From this analysis, it is possible to identify the key knowledge objects that have salience to each phase of operation. For the purpose of this analysis, salience is defined as those knowledge objects that serve as a central hub to other knowledge objects (i.e., have five or more links to other knowledge objects). This criterion produces a list of twelve knowledge objects from a pool of sixty four (approximately one fifth of the total number of knowledge objects). The objects are: intent, weapons, scenarios, threat, range, engage, radar, targets, status, intelligence, platform and hit potential. The purpose of this analysis is to identify knowledge objects that play a central role in the threat tasks. Each of these core knowledge objects is represented in a generic table against each stage for the purpose of highlighting its role.

As table 3 shows, different core knowledge objects are salient at different points in the operation (e.g., intent is relevant at the plan, allocate, engage, reassess and posture phases, whereas intelligence is relevant only in the plan phase). The passing of knowledge objects from one phase to another involves some manipulation of the object before it is passed and then means of communicating the nature of the object (for example the priority of targets are assessed before weapon systems are allocated to them and then they may be engaged), either implicitly or explicitly.

Table 4. Analysis of core knowledge objects within the seven phases of operation

\begin{tabular}{|c|c|c|c|c|c|c|c|}
\hline $\begin{array}{l}\text { Knowledge } \\
\text { Objects }\end{array}$ & $\begin{array}{l}\text { Plan } \\
\text { task }\end{array}$ & $\begin{array}{l}\text { Identify } \\
\text { task }\end{array}$ & $\begin{array}{l}\text { Allocate } \\
\text { task }\end{array}$ & $\begin{array}{l}\text { Engage } \\
\text { task }\end{array}$ & $\begin{array}{l}\text { Reassess } \\
\text { task }\end{array}$ & $\begin{array}{l}\text { Control } \\
\text { task }\end{array}$ & $\begin{array}{l}\text { Posture } \\
\text { task }\end{array}$ \\
\hline Intent & & & & & & & \\
\hline Weapons & & & & & & & \\
\hline Scenarios & & & & & & & \\
\hline Threat & & & & & & & \\
\hline Range & & & & & & & \\
\hline Engage & & & & & & & \\
\hline Radar & & & & & & & \\
\hline Targets & & & & & & & \\
\hline Status & & & & & & & \\
\hline Intelligence & & & & & & & \\
\hline Platform & & & & & & & \\
\hline Hit potential & & & & & & & \\
\hline Count of KOs & $7 / 12$ & $5 / 12$ & $8 / 12$ & $10 / 12$ & $8 / 12$ & $9 / 12$ & $10 / 12$ \\
\hline
\end{tabular}

The purpose of this analysis is that it brings all three representations together, namely the social network (i.e., whom is communicating with whom), the task network (i.e., the goals of what is being done) and the knowledge network (i.e., the key features of 
situation awareness for each phase of operation). The HMS Dryad type 23 operations control room studies showed highly complex interaction between crew and communication channels. It is an extremely intense environment and over a relatively short period of time (approximately two hours) an enormous amount of communications occurred with information being transferred.

The methods indicate that there is a lot of teamwork occurring in each scenario although there is a clear hierarchy. The PWO and AAWO still remain the central nodes of the operations room. Information is shared between the crew members however the majority of this information seems to be shared via the PWO and AAWO.

Shared awareness can be seen from the analysis in table four. Many of the knowledge objects are shared within the three individual scenarios (i.e., air, surface and subsurface) as well as across the whole mission. It is important to remember that the three scenarios observed will often happen at the same time and will not be separated into three clear areas. Thus the sharing of knowledge objects across scenarios will be essential for effective operations.

There is the implication that distributed situation awareness could be viewed in terms of the activated knowledge objects, and these activations change over the course or phases of a mission. This has implications for workload and levels of uncertainty. We speculate that the workload and uncertainty might increase with the number of knowledge objects that need to be managed. Workload might simply increase because there is more knowledge to manage whereas uncertainty might increase because there are more things to keep track of. This hypothesis requires further empirical investigation. The results of this application of the methodology are intended to form a part of wider data collection and analysis with a view to developing a generic model of command and control.

Now that the network models have been defined, it should be possible to consider the potential effects of changes in those networks. As mentioned in the introduction to this paper, these questions include addressing the effects of changing the task, social or propositional networks and the subsequent effects on DSA, workload, error rates, 
timeliness of response, and overall mission effectiveness. This will be the focus of our subsequent research.

\section{Conclusions}

The idea that there exists a network of knowledge objects for the entire system raises some interesting points about shared awareness. First, we claim that it the system as a whole, rather than a given individual, that holds all relevant knowledge; individuals have different views of this network. Second, the view that an individual has must be sufficient to support the activity that they perform, i.e., command activity requires high-level awareness of a wide range of knowledge objects, whereas target tracking requires low-level, detailed awareness of a subset of knowledge objects. Third, the 'sharing' of awareness does not necessarily entail communication between individuals - it might be confusing or misleading if all individuals attempted to share all of their separate views of the situation. Rather, it is important for the agents within a system to have awareness of who is likely to hold specific views and, consequently, to interpret that potential usefulness of information that can be passed through the network in terms of these views. Extending the DSA to Endsley's conception of SA would mean that some individuals are engaged in perception tasks (such as the picture compilers and picture supervisors), some are engaged in comprehension and in the projection tasks (such as the anti-air warfare officer and the principle warfare officer) and other are engaged in the response execution tasks (such as the missile directors and the electronic warfare director). Thus, referring back to the DSA analysis of the fire-fighting system, we argue that the theory and method work equally well with single person-machine systems as well as large multi-person machine systems, as DSA is concerned with how knowledge is used and parsed between agents in systems interaction.

Indeed, this latter point may even hold the key to DSA. Assuming that performance will be most effective when there is 'good' DSA throughout the system as a whole, it follows that the network links are more crucial than the nodes themselves in maintaining DSA. Moreover, there are then two aspects of SA at any given node: individual SA of one's own task, and a 'meta-SA' of the whole system's DSA. Given that effective team working depends on information transfer across the network links, 
knowing which links to use (and where to offer information when needed) will really determine the quality of DSA, and is thus perhaps the truest description of DSA itself. The Distributed Cognition approach has been successfully used to analyse the cognitive properties of a variety of environments (Perry, 2003), adding to our understanding of the cognitive processes that are taking place, over and above information gleaned from studies concentrating solely on individual cognition (Flor and Hutchins, 1991). It has also highlighted a new level of study for other research areas, including DSA. The DSA approach does not dispute that the individuals in the system will have their own awareness of a situation, or that groups of individuals may share some level of understanding of the situation (Artman and Garbis, 1998). It is asserted that complex problem-solving systems will have their own cognitive properties (including SA) that cannot be accounted for by individual cognition and that to study a system at the level of the individual will fail to pick up on these systems level features (Hutchins, 1995; Perry, 2003).

The knowledge and task networks described in figures 8 to 15 are based on observational data and provide us with model exemplars of DSA for specific tasks in this environment. These could then be used to diagnose problems in system performance where such problems are attributed to failures in DSA. Taking the models one step further, it may even be possible to use the networks in a predictive fashion to run simulations of different task structures. The DSA approach therefore has implications for the design of the working environment, e.g. in terms of team structure, which can impact the flow of information through the system; and HCI, due to the importance of technological artefacts in distributed environments (Artman, 2000).

By viewing SA first as a systems-level phenomenon, it is possible to identify the aspects of a situation about which agents require knowledge. By viewing the active knowledge in each state of an incident, it is possible to determine who knows what at a given time. From this perspective, it becomes possible to indicate how information needs to disseminate through the system for effective performance and to identify possible barriers to effective dissemination. One of the keys to effective DSA are links, since you can’t have DSA without communication. The graphical representation provides a simple but effective means by which system SA can be 
mapped. From this work we further propose that adding additional communications requirements (through which agents share or communicate their mental models) can add significant burden to the processes and may actually impede SA by: (i.) introducing tasks that might serve to activate additional but unnecessary nodes in the network; (ii.) introduce time-delay between receiving and acting upon information; (iii.) inappropriate emphasis on some links in the network. The challenge for now is to continue to collect evidence that will enable us to substantiate this theory. In particular, our work focuses on the question of how best to describe SA at a system's level and how communication between agents within a system can support effective performance.

\section{Acknowledgements}

This research from the Human Factors Integration Defence Technology Centre was part-funded by the Human Sciences Domain of the UK Ministry of Defence Scientific Research Programme. The research team would also like to thank the staff at HMS Dryad and HMS Collingwood for their assistance in allowing us to study the type 23 operations control room, which made this research possible.

\section{References}

Annett, J. 2005 Hierarchical task analysis. In: Stanton, N. A., Hedge, A., Salas, E., Hendrick, H. \& Brookhaus, K. (eds) Handbook of Human Factors and Ergonomics Methods. London: Taylor and Francis (33-1 - 33-7).

Annett, J; Cunningham, D. J. \& Mathias-Jones, P. (2000) A method for measuring team skills. Ergonomics, 43, 1076-1094.

Anderson, J.R. (1980) Cognitive Psychology and its Implications, San Francisco, CA: Freeman

Artman, H. (2000). Team situation assessment and information distribution Ergonomics, 43 (8), 1111-1128 
Artman, H. \& Garbis, C. (1998) Situation Awareness as Distributed Cognition. In T.R.G. Green, L. Bannon, C.P. Warren and J. Buckley (Eds) ECCE 9: Proceedings of the Ninth European Conference on Cognitive Ergonomics, 151156. European Association of Cognitive Ergonomics (EACE), Le Chesnay, France.

Ashleigh, M.J. \& Stanton, N.A. 2001, Trust: key elements in human supervisory control domains, Cognition, Work \& Technology, 3, 92-100.

Bainbridge, L. and Sanderson, P. (1995) Verbal Protocol Analysis, In J.R. Wilson and E.N. Corlett (eds) Evaluation of Human Work, London :Taylor and Francis, $169-201$

Bell, H.H. \& Lyon, D.R., (2000), Using Observer Ratings To Assess Situation Awareness, In: M.R. Endsley (Ed.) Situation Awareness Analysis and Measurement, Mahwah, NJ: LEA, 129-146

Collins, A.M. and Loftus, E.F. (1975) A spreading-activation theory of semantic processing, Psychological Review, 82 407-428

Endlsey M. R. 1995, Toward a theory of situation awareness in dynamic systems, Human Factors, 37, 32-64

Flanagan, J. C. (1954) The critical incident technique, Psychological Bulletin, 51, 327-358.

Flor, N.V. and Hutchins, E.L. (1991) Analyzing Distributed Cognition in Software Teams: A Case Study of Team Programming during Perfective Software Maintenance. In J. Koenemann-Belliveau, T. G. Moher and S. P. Robertson (Eds.) Empirical Studies of Programmers: Fourth Workshop. 36-64. Norwood, New Jersey: Ablex 
Hancock, P. A. (1997) Essays on the Future of Human-Machine Systems. Minneapolis, MN: Banta Press.

Hollnagel, E. 1993, Human Reliability Analysis - Context and Control. London: Academic Press.

Houghton, R. J., Baber, C., McMaster, R., Stanton, Salmon, P., Stewart, R. and Walker, G. (2005) Command and control in emergency services operations: A social network analysis. Ergonomics (this issue)

Houghton, R.J., Baber, C. and Cowton, M., 2005, Development of the WESTT human performance analysis tool, In P.D. Bust and P.T. McCabe (eds) Contemporary Ergonomics 2005, London: Taylor and Francis, 336-339

Hutchins, E. (1995), How a Cockpit Remembers Its Speeds. Cognitive Science, 19 (3), 265-288

Hutchins, E. (1991) The technology of team navigation, In J. Galegher, R.E. Kraut and C. Egido (eds) Intellectual Teamwork, Hillsdale, NJ: LEA, 191-220

Klein, G.A.,1989, Recognition-Primed Decisions, In W.B. Rouse (Ed) Advances In Man-Machine Systems Research Volume 5, Greenwich, Ct: Jai, 47-92

Klein, G. and Armstrong, A. A. 2005 Critical Decision Method In: Stanton, N. A., Hedge, A., Salas, E., Hendrick, H. \& Brookhaus, K. (eds) Handbook of Human Factors and Ergonomics Methods. London: Taylor and Francis (35-1 - 33-8).

Kirwan, B. 1994 A Guide to Practical Human Reliability Assessment. London: Taylor and Francis.

Meister, D. 1989, Conceptual Aspects of Human Factors, Baltimore, MD: John Hopkins Press. 
Muir, B. M. 1994, Trust in automation: Part 1. Theoretical issues in the study of trust and human intervention in automated systems. Ergonomics, 37, 19051922.

Muir, B. M. \& Moray, N. 1996, Trust in automation: Part 2. Experimental studies of trust and human intervention in process control simulation. Ergonomics, 39, 429-460.

Ogden, G.C. (1987) Concept, knowledge and thought, Annual Review of Psychology, $38 \quad 203-227$

Paris, C. R.; Salas, E. \& Cannon-Bowers, J. A. (2000) Teamwork In Multi-Person Systems: a Review And Analysis. Ergonomics, 43 (8), 1052-1075

Perry, M. (2003) Distributed cognition, In J.M. Carroll (ed) HCI Models, Theories and Frameworks, San Francisco, CA: Morgan-Kaufmann, (93-224)

O’Hare, D., Wiggins, M., Williams, A., \& Wong, W. (2000). Cognitive task analyses for decision centred design and training. In J. Annett \& N. Stanton (eds) Task Analysis, London, Taylor and Francis, (170-190).

Quillian, R. (1969) The teachable language comprehender: a simulation program and theory of language, Communications of the ACM, 12459-476

Rasmussen, J. 1986, Information Processing and Human Machine Interaction. New York: North-Holland.

Salvendy, G. 1997 Handbook of Human Factors and Ergonomics, $2^{\text {nd }}$ edition, New York: Wiley.

Smith, K. \& Hancock, P. A. 1995, Situation awareness is adaptive, externally directed consciousness, $\underline{\text { Human Factors }}$ 37, 137-148 
Stanton, N. A., Baber, C., Walker, G. H., Salmon, P., \& Green, D. (2004). Toward a Theory of Agent-Based Systemic Situational Awareness. In In D. A. Vincenzi, M. Mouloua, \& P. A. Hancock (Eds.), Proceedings of the Second Human Performance, Situation Awareness and Automation Conference (HPSAAII), Daytona Beach, FL, March 22-25.

Singeton, T. 1989, The Mind at Work. Cambridge: Cambridge University Press.

Stanton, N. A.; Ashleigh, M. J.; Roberts, A, D. and Xu, F. 2004, Levels of abstraction in human supervisory control teams. Submitted to Computers, Technology and Work

Vicente, K. 1999, Cognitive Work Analysis. Mahwah, NJ: Lawrence Erlbaum Associates.

Walker, G. H.; Gibson, H.; Stanton, N. A. \& Baber, C. (2005) EAST (Event Analysis of Systemic Teamwork): A novel integration of ergonomics methods to analyse C4i activity, Ergonomics (this issue)

Wilson, J. R. and Corlett, E. N. 1995, Evaluation of Human Work, $2^{\text {nd }}$ edition, London: Taylor \& Francis 